\title{
Compassionate Communities and Their Role in End-of-Life Care
}

\author{
Christopher Russell, BHSc ${ }^{1}$
}

${ }^{1}$ Faculty of Medicine, University of Ottawa

\section{A B STRACT}

Death is a universal experience that has often been underrepresented in discussion between loved ones and the healthcare system. Given the need for support throughout all aspects of end-of-life care, an emerging paradigm shift shows Compassionate Communities as a new standard for placing responsibility back in the community and promoting respectful and compassionate care. Development of Compassionate Communities promotes quality end-of-life care designed to meet the individualized needs of the dying as well as their caregivers.

\section{RÉ S U MÉ}

La mort est une expérience universelle qui a souvent été sous-représentée lors de discussions entre les proches d'une personne mourante et le système de soins de santé. Étant donné le besoin de soutien au niveau des diverses facettes des soins de fin de vie, un changement émergent de paradigme démontre que les Communautés bienveillantes sont dorénavant la norme pour confier à nouveau la responsabilité aux communautés, et pour promouvoir des soins respectueux et compatissants. Le développement des Communautés Bienveillantes promeut des soins de fin de vie de qualité, conçus pour répondre aux besoins particuliers des personnes mourantes ainsi que de leurs aides.

The topics of dying and bereavement are ones that are difficult to discuss, yet are universally experienced [1,2]. A growing need can be seen to address concerns regarding the disconnect between end-of-life wishes, and what happens in reality $[1,3]$. A huge barrier in existence to those who are dying is the taboo of discussing death, and the subsequent lack of communication with friends, family, and healthcare providers $[1,3]$. Responsibility can be found in all stakeholders with regard to the lack of end-of-life discussions: patients, who may be fearful or shy to discuss endof-life issues; family or significant others, who may be unwilling to accept or discuss patient preferences; and healthcare providers, who may feel they lack knowledge on advanced directives or how to deliver bad news [4]. Furthermore, a lack of ability to discuss death and loss can be detrimental to bereavement after the loss of a loved one [1]. These issues are highly personalized and experienced in a unique way by each person. Pallium Canada, an organization focused on interprofessional education in palliative and end-of-life care, sees issues surrounding death, dying, loss, and bereavement as a public health concern [1,2]. This concept highlights the importance of addressing key topics in end-of-life care and begs the question: How can such personalized needs be addressed?

Perhaps the most promising answer to this question is a social transformation towards Compassionate Communities [2,5]. A global movement, the Charter for Compassion International, has led the development of a "Charter of Compassion," which states that beneath any inequities or indifference, there is a deep compassion within everyone, which compels us to care for one an- other $[6,7]$. "In a Compassionate Community," it reads, "people are motivated by compassion to take responsibility for, and care for each other." [7] This paradigm shift calls on the community, not just the healthcare system, to support end-of-life care and bereavement $[2,5]$. Focusing on the need to mobilize a community, and placing accountability on the people to support one another, Compassionate Communities concentrate on creating partnerships within the community $[2,5]$. Their goal is to address gaps in any aspect of end-of-life care through collaboration [2,5].

With Compassionate Communities using partnerships to mobilize a community to address concerns and take responsibility for its neighbours, it is clear that this model could be used to address a wide variety of social issues. In the context of end-of-life care, one must next examine how this model can tie into the themes that Pallium Canada identified, namely death, dying, loss, and bereavement.

One common disconnect seen in those who are dying is the desired location to die. The Dying Matters Coalition in the United Kingdom found that approximately $70 \%$ of people express a desire to die in the comfort of their home, yet around $60 \%$ die in hospital [1]. While a multitude of factors might influence this, one common narrative seen is caregiver burnout that leads to an emergency hospital admission in the final days of life [3]. This may stem from the perception that healthcare providers play the primary role in providing care while caregivers provide support, as opposed to viewing the healthcare field as a support for the caregiver's team [3]. This shift towards a caregiver-centered ap- 
proach to end-of-life care represents a change from the classic service delivery approach to palliative care, and opens doors for the needs of this model to be filled by a Compassionate Community [3]. The community can take on several roles, such as supporting caregivers in daily activities to avoid burnout, providing companionship to the dying while giving caregivers respite, promoting conversations on death and end-of-life planning, and helping to identify resources for the dying and their loved ones [3]. This process would involve mobilizing the community to create volunteers who reach out and initiate conversations on wishes and integrate healthcare, family, the person, and their community, in order to help them view the process of death holistically [3]. This entire process might allow for support networks to be better formed, prevent burnout in primary caregivers and improve their mental health, and allow for wishes such as dying at home to become a more common reality.

The support of one's community not only benefits those who are dying, but also remains after loved ones have passed to support those who have suffered a loss. There are two exemplary illustrations of Compassionate Community initiatives here in Ontario: the Windsor-Essex and Niagara West Compassionate Communities $[8,9]$.

The Windsor-Essex Compassionate Community has developed what they see as five key pillars to make meaningful change in their community [8]. The first concentrates on mobilizing members of the community to connect and organize support for those who need it, focusing on the skills that individuals can offer [8]. The second is the creation of a distress network, which any member of the community can contact if they have concerns that they themselves, or someone they know, are falling through the cracks of the system [8]. The third pillar calls for the creation of community volunteers to reach out to those who are suffering and their caregivers, helping to establish goals of care and to identify available community resources and volunteer services [8]. The fourth pillar involves undertaking partnerships with agencies in the community to explore how their resources can be utilized and to collect data to determine feasibility and continue making improvements within this structure [8]. Finally, the fifth pillar proposes partnerships within all levels of government, from federal to municipal, to create a "Community Trust" that tackles both short-term and long-term expansion and development of their Compassionate Community principles [8]. Being a member of one of these communities might improve negative perceptions surrounding end-of-life care, creating a preventative solution to reducing stress and improving mental health in both the dying and their caregivers. It is clear how this focus on creating community support, ensuring all are able to access and utilize services, and on continued improvement, would create an environment in which the wishes of the dying and the needs of their caregivers would be both heard and addressed, using not only the healthcare system, but the compassion of fellow neighbours.

The Niagara West Compassionate Community initiative has also identified the strength of compassion, and has focused on supporting those who have lost a loved one [8]. While the desire to help those who are suffering was found in full force within the community, members felt as though they lacked confidence and knowledge to truly be of benefit to those who are bereaving [9]. The presence of a Bereavement Support Clinician in this community has been essential in building the capacity of members of the community to feel ready to support others [9]. Through listening to community members' needs and creating training programs and resources to bridge gaps in knowledge or abilities, the healthcare team is able to back away and allow members of the community to begin caring for one another [9]. This sustainable model has led to the creation of a wide variety of support networks and initiatives to address bereavement, including: cooking classes for spouses or families where one can remember their loved one through recipes; movie nights aimed at promoting conversations around death and dying; and community-run yoga events, meditation groups, and walking clubs, all facilitated by members of the community trained in bereavement support [9]. This model of Compassionate Communities highlights the importance of identifying the need for certain programs within a community, and the role of the healthcare system in supporting their creation, while ensuring that they become self-sustaining.

Both of these models represent an evolution in the practice of palliative care, moving away from seeing the dying as a patient rather than a person, and building capacity within communities to be large supporters of end-of-life care $[3,8,9]$. While this evolution might seem natural to some, it can be difficult to create an environment in which a Compassionate Community can be formed and have enough support to flourish [3]. One approach to this issue could be the formation of a Community of Practice. A Community of Practice is formed by people who engage in a process of collective learning, who share a concern or passion for something they do, and who learn how to do it better as they interact regularly $[10,11]$. By engaging stakeholders within a community, including healthcare, government, and volunteer organizations, a common goal of creating a Compassionate Community could be the driving force for a Community of Practice. Though none may be experts at first, by examining the successes of Compassionate Communities within Ontario, adopting practices, creating initiatives in their own communities, and constantly reevaluating their needs, successes, and future directions, a Community of Practice would be able to grow and become a leader in end-of-life care.

One can see that in order to drastically change the landscape of end-of-life care, participation in caregiving must move beyond current stakeholders. Creating Communities of Practice focused 
on implementing the values of Compassionate Communities would promote a fertile environment for community-based endof-life care that sees each person as unique and adapts to meet the needs of both patients and caregivers, thereby reducing individual burden and burnout, and improving the experience for all.

\section{REFERENCES}

1. Dying Matters Coalition. Why should we develop compassionate communities? [Internet]. [cited 2016 Feb 28]. Available from: http://www.dyingmatters.org/sites/default/files/user/documents/Resources/Community\%20 Pack/1-Introduction-1.pdf.

2. Pallium Canada. Compassionate Communities (CC) [Internet]. [cited 2016 Feb 29]. Available from: http://pallium.ca/compassionate-communities-2/.

3. Abel J, Bowra J, Walter T, Howarth G. Compassionate community networks: Supporting home dying. BMJ Support Palliat Care. 2011;1(2):129-33.

4. Larson DG, Tobin DR. End-of-life conversations: Evolving practice and theory. JAMA. 2000;284(12):1573-8.

5. Pallium Canada. Compassionate Communities 101 [Internet]. [cited 2016 Feb 29]. Available from: http://pallium.ca/compassionate-communities-2/ what-is-health-promoting-palliative-care/.

6. Turkovich M. The Charter for Compassion [Internet]. [cited 2016 Feb 28]. Available from: http://www.charterforcompassion.org/index.php/charter/.

7. Chapter 2. Other Models for Promoting Community Health and Development | Section 16. Building Compassionate Communities | Main Section | Community Tool Box [Internet]. [cited 2016 Feb 29]. Available from: http:// ctb.ku.edu/en/table-of-contents/overview/models-for-community-healthand-development/building-compassionate-communities/main.

8. Pallium Canada. CC Windsor-Essex [Internet]. [cited 2016 Mar 1]. Available from: http://pallium.ca/compassionate-communities-2/canadian-compassionate-communities-projects/cc-windsor-essex/.

9. Pallium Canada. CC Niagara West [Internet]. [cited 2016 Mar 1]. Available from: http://pallium.ca/compassionate-communities-2/canadian-compassionate-communities-projects/cc-niagara-west/.

10. Pallium Canada. CC Community of Practice [Internet]. [cited 2016 Mar 1]. Available from: http://pallium.ca/compassionate-communities-2/community-of-practice/.

11. Wenger-Trayner. Introduction to communities of practice [Internet]. [cited 2016 Mar 1]. Available from: http://wenger-trayner.com/introduction-tocommunities-of-practice/. 